\title{
S1 References
}

References ordered alphabetically by first author

s1. Alvarado AG, Turaga SM, Sathyan $P$, et al. Coordination of self-renewal in glioblastoma by integration of adhesion and microRNA signaling. Neuro-oncology. 2016;18(5):656666. doi:10.1093/neuonc/nov196

s2. Bayin N.S., Frenster J.D., Kane J.R., et al. GPR133 (ADGRD1), an adhesion G-proteincoupled receptor, is necessary for glioblastoma growth. Oncogenesis. 2016;5(10):e263. doi:10.1038/oncsis.2016.63

s3. Cai H.-Q., Liu A.-S., Zhang M.-J., et al. Identifying Predictive Gene Expression and Signature Related to Temozolomide Sensitivity of Glioblastomas. Frontiers in Oncology. 2020;10((Cai, Liu, Liu, Meng, Qian) Department of Neurosurgery, National Cancer Center/National Clinical Research Center for Cancer/Cancer Hospital, Chinese Academy of Medical Sciences and Peking Union Medical College, Beijing, China(Zhang, Wan) Department of Neu):669. doi:10.3389/fonc.2020.00669

s4. Delic S, Lottmann N, Stelzl A, et al. MiR-328 promotes glioma cell invasion via SFRP1dependent Wnt-signaling activation. Neuro-oncology. 2014;16(2):179-190.

doi:10.1093/neuonc/not164

s5. Deng S, Li Y, Yi G, et al. Overexpression of COX7A2 is associated with a good prognosis in patients with glioma. Journal of neuro-oncology. 2018;136(1):41-50. doi:10.1007/s11060-017-2637-z

s6. Erhart F., Weiss T., Klingenbrunner S., et al. Spheroid glioblastoma culture conditions as antigen source for dendritic cell-based immunotherapy: spheroid proteins are survival-relevant targets but can impair immunogenic interferon gamma production. Cytotherapy. 2019;21(6):643-658. doi:10.1016/j.jcyt.2019.03.002

s7. Erhart F, Blauensteiner B, Zirkovits G, et al. Gliomasphere marker combinatorics: multidimensional flow cytometry detects CD44+/CD133+//TGA6+/CD36+ signature. Journal of cellular and molecular medicine. 2019;23(1):281-292. doi:10.1111/jcmm.13927

s8. Genovese G., Ergun A., Shukla S.A., et al. microRNA regulatory network inference identifies miR-34a as a novel regulator of TGF-beta signaling in glioblastoma. Cancer Discovery. 2012;2(8):736-749. doi:10.1158/2159-8290.CD-12-0111

s9. Guo R-M, Zhao C-B, Li P, Zhang L, Zang S-H, Yang B. Overexpression of CLEC18B Associates With the Proliferation, Migration, and Prognosis of Glioblastoma. ASN neuro. 2018;10(101507115):1759091418781949. doi:10.1177/1759091418781949

s10. Haapa-Paananen S, Chen P, Hellstrom K, et al. Functional profiling of precursor MicroRNAs identifies MicroRNAs essential for glioma proliferation. PloS one. 2013;8(4):e60930. doi:10.1371/journal.pone.0060930

s11. Hasan T, Caragher SP, Shireman JM, et al. Interleukin-8/CXCR2 signaling regulates therapy-induced plasticity and enhances tumorigenicity in glioblastoma. Cell death \& disease. 2019;10(4):292. doi:10.1038/s41419-019-1387-6

s12. Ho K-H, Chen P-H, Hsi E, et al. Identification of IGF-1-enhanced cytokine expressions targeted by miR-181d in glioblastomas via an integrative miRNA/mRNA regulatory network analysis. Scientific reports. 2017;7(1):732. doi:10.1038/s41598-017-00826-0 
s13. Holmberg Olausson K, Maire CL, Haidar S, et al. Prominin-1 (CD133) defines both stem and non-stem cell populations in CNS development and gliomas. PloS one.

2014;9(9):e106694. doi:10.1371/journal.pone.0106694

s14. Hong L, Ya-Wei L, Hai W, et al. MiR-519a functions as a tumor suppressor in glioma by targeting the oncogenic STAT3 pathway. Journal of neuro-oncology. 2016;128(1):35-45. doi:10.1007/s11060-016-2095-z

s15. Hu Y, Ylivinkka I, Chen $\mathrm{P}$, et al. Netrin-4 promotes glioblastoma cell proliferation through integrin beta4 signaling. Neoplasia (New York, NY). 2012;14(3):219-227.

s16. Hua T.N.M., Oh J., Kim S., et al. Peroxisome proliferator-activated receptor gamma as a theragnostic target for mesenchymal-type glioblastoma patients. Experimental and Molecular Medicine. 2020;52(4):629-642. doi:10.1038/s12276-020-0413-1

s17. Jarboe JS, Anderson JC, Duarte CW, et al. MARCKS regulates growth and radiation sensitivity and is a novel prognostic factor for glioma. Clinical cancer research : an official journal of the American Association for Cancer Research. 2012;18(11):30303041. doi:10.1158/1078-0432.CCR-11-3091

s18. Kinker GS, Oba-Shinjo SM, Carvalho-Sousa CE, et al. Melatonergic system-based twogene index is prognostic in human gliomas. Journal of pineal research. 2016;60(1):8494. doi:10.1111/jpi.12293

s19. Klopfenstein Q, Truntzer C, Vincent J, Ghiringhelli F. Cell lines and immune classification of glioblastoma define patient's prognosis. British journal of cancer. 2019;120(8):806-814. doi:10.1038/s41416-019-0404-y

s20. Kuang J-Y, Guo Y-F, Chen Y, et al. Connexin 43 C-terminus directly inhibits the hyperphosphorylation of Akt/ERK through protein-protein interactions in glioblastoma. Cancer science. 2018;109(8):2611-2622. doi:10.1111/cas.13707

s21. Kudo T., Prentzell M.T., Mohapatra S.R., et al. Constitutive Expression of the Immunosuppressive Tryptophan Dioxygenase TDO2 in Glioblastoma Is Driven by the Transcription Factor C/EBPbeta. Frontiers in Immunology. 2020;11((Kudo, Sahm, Platten, Green) DKTK CCU Neuroimmunology and Brain Tumor Immunology, German Cancer Research Center (DKFZ), Heidelberg, Germany(Kudo, Platten, Green) Department of Neurology, Medical Faculty Mannheim, Heidelberg University, Mannheim, Germany(K):657. doi:10.3389/fimmu.2020.00657

s22. Li H, Li J, Chen L, et al. HERC3-Mediated SMAD7 Ubiquitination Degradation Promotes Autophagy-Induced EMT and Chemoresistance in Glioblastoma. Clinical cancer research : an official journal of the American Association for Cancer Research. 2019;25(12):3602-3616. doi:10.1158/1078-0432.CCR-18-3791

s23. Li L, Huang Y, Gao Y, et al. EGF/EGFR upregulates and cooperates with Netrin-4 to protect glioblastoma cells from DNA damage-induced senescence. BMC cancer. 2018;18(1):1215. doi:10.1186/s12885-018-5056-4

s24. Liu Y, Li X, Zhang Y, et al. An miR-340-5p-macrophage feedback loop modulates the progression and tumor microenvironment of glioblastoma multiforme. Oncogene. 2019;38(49):7399-7415. doi:10.1038/s41388-019-0952-x 
s25. Luedi MM, Singh SK, Mosley JC, et al. A Dexamethasone-regulated Gene Signature Is Prognostic for Poor Survival in Glioblastoma Patients. Journal of neurosurgical anesthesiology. 2017;29(1):46-58.

s26. Luedi MM, Singh SK, Mosley JC, et al. Dexamethasone-mediated oncogenicity in vitro and in an animal model of glioblastoma. Journal of neurosurgery. 2018;129(6):14461455. doi:10.3171/2017.7.JNS17668

s27.Mao D.D., Gujar A.D., Mahlokozera T., et al. A CDC20-APC/SOX2 Signaling Axis Regulates Human Glioblastoma Stem-like Cells. Cell Reports. 2015;11(11):1809-1821. doi:10.1016/j.celrep.2015.05.027

s28. Marziali G, Signore M, Buccarelli M, et al. Metabolic/Proteomic Signature Defines Two Glioblastoma Subtypes With Different Clinical Outcome. Scientific reports.

2016;6(101563288):21557. doi:10.1038/srep21557

s29. Mega A, Hartmark Nilsen M, Leiss LW, et al. Astrocytes enhance glioblastoma growth. Glia. 2020;68(2):316-327. doi:10.1002/glia.23718

s30. Mehrian-Shai R, Yalon M, Simon AJ, et al. High metallothionein predicts poor survival in glioblastoma multiforme. BMC medical genomics. 2015;8(101319628):68. doi:10.1186/s12920-015-0137-6

s31. Mikheev AM, Mikheeva SA, Severs LJ, et al. Targeting TWIST1 through loss of function inhibits tumorigenicity of human glioblastoma. Molecular oncology. 2018;12(7):11881202. doi:10.1002/1878-0261.12320

s32. Nduom EK, Wei J, Yaghi NK, et al. PD-L1 expression and prognostic impact in glioblastoma. Neuro-oncology. 2016;18(2):195-205. doi:10.1093/neuonc/nov172

s33. Okura H, Golbourn BJ, Shahzad U, et al. A role for activated Cdc42 in glioblastoma multiforme invasion. Oncotarget. 2016;7(35):56958-56975.

doi:10.18632/oncotarget.10925

s34.Pandya P., Jethva M., Rubin E., Birnbaum R.Y., Braiman A., Isakov N. PICOT binding to chromatin-associated EED negatively regulates cyclin D2 expression by increasing H3K27me3 at the CCND2 gene promoter. Cell Death and Disease. 2019;10(10):685. doi:10.1038/s41419-019-1935-0

s35.Pangeni RP, Zhang Z, Alvarez AA, et al. Genome-wide methylomic and transcriptomic analyses identify subtype-specific epigenetic signatures commonly dysregulated in glioma stem cells and glioblastoma. Epigenetics. 2018;13(4):432-448. doi:10.1080/15592294.2018.1469892

s36. Paul Y., Thomas S., Patil V., et al. Genetic landscape of long noncoding RNA (IncRNAs) in glioblastoma: Identification of complex IncRNA regulatory networks and clinically relevant IncRNAs in glioblastoma. Oncotarget. 2018;9(51):29548-29564. doi:10.18632/oncotarget.25434

s37.Pollak J, Rai KG, Funk CC, et al. Ion channel expression patterns in glioblastoma stem cells with functional and therapeutic implications for malignancy. PloS one. 2017;12(3):e0172884. doi:10.1371/journal.pone.0172884 
s38. Polonen P, Jawahar Deen A, Leinonen HM, et al. Nrf2 and SQSTM1/p62 jointly contribute to mesenchymal transition and invasion in glioblastoma. Oncogene. 2019;38(50):7473-7490. doi:10.1038/s41388-019-0956-6

s39. Qiu S, Huang D, Yin D, et al. Suppression of tumorigenicity by microRNA-138 through inhibition of EZH2-CDK4/6-pRb-E2F1 signal loop in glioblastoma multiforme. Biochimica et biophysica acta. 2013;1832(10):1697-1707. doi:10.1016/j.bbadis.2013.05.015

s40. Rowther FB, Wei W, Dawson TP, et al. Cyclic nucleotide phosphodiesterase-1C (PDE1C) drives cell proliferation, migration and invasion in glioblastoma multiforme cells in vitro. Molecular carcinogenesis. 2016;55(3):268-279. doi:10.1002/mc.22276

s41. Safaee M, Clark AJ, Oh MC, et al. Overexpression of CD97 confers an invasive phenotype in glioblastoma cells and is associated with decreased survival of glioblastoma patients. PloS one. 2013;8(4):e62765. doi:10.1371/journal.pone.0062765

s42. Sana J, Busek P, Fadrus $P$, et al. Identification of microRNAs differentially expressed in glioblastoma stem-like cells and their association with patient survival. Scientific reports. 2018;8(1):2836. doi:10.1038/s41598-018-20929-6

s43. Sathyan P, Zinn PO, Marisetty AL, et al. Mir-21-Sox2 Axis Delineates Glioblastoma Subtypes with Prognostic Impact. The Journal of neuroscience : the official journal of the Society for Neuroscience. 2015;35(45):15097-15112. doi:10.1523/JNEUROSCI.126515.2015

s44. Shahar T, Rozovski U, Hess KR, et al. Percentage of mesenchymal stem cells in highgrade glioma tumor samples correlates with patient survival. Neuro-oncology. 2017;19(5):660-668. doi:10.1093/neuonc/now239

s45. Sharma A., Bendre A., Mondal A., Muzumdar D., Goel N., Shiras A. Angiogenic gene signature derived from subtype specific cell models segregate proneural and mesenchymal glioblastoma. Frontiers in Oncology. 2017;7(JUL):146. doi:10.3389/fonc.2017.00146

s46. Shi Y, Chen C, Yu S-Z, et al. miR-663 Suppresses Oncogenic Function of CXCR4 in Glioblastoma. Clinical cancer research : an official journal of the American Association for Cancer Research. 2015;21(17):4004-4013. doi:10.1158/1078-0432.CCR-14-2807

s47.Shugg T., Dave N., Amarh E., Assiri A.A., Pollok K.E., Overholser B.R. Letrozole targets the human ether-a-go-go-related gene potassium current in glioblastoma. Basic and Clinical Pharmacology and Toxicology. 2020;((Shugg, Amarh, Assiri, Overholser) Department of Pharmacy Practice, Purdue University College of Pharmacy, West Lafayette, IN, United States(Shugg, Dave, Amarh, Overholser) Division of Clinical Pharmacology, Indiana University School of Medicine, Indianap). doi:10.1111/bcpt.13515

s48. Stegen B, Butz L, Klumpp L, et al. Ca2+-Activated IK K+ Channel Blockade Radiosensitizes Glioblastoma Cells. Molecular cancer research : MCR. 2015;13(9):1283-1295. doi:10.1158/1541-7786.MCR-15-0075

s49.Wang C., Zhao N., Zheng Q., Zhang D., Liu Y. BHLHE41 promotes U87 and U251 cell proliferation via ERK/cyclinD1 signaling pathway. Cancer Management and Research. 2019;11((Wang, Zhao, Zheng, Zhang, Liu) Department of Pathology, College of Basic Medical Sciences, China Medical University, Shenyang 110122, China(Wang, Zhao, 
Zheng, Zhang, Liu) Department of Pathology, The First Affiliated Hospital, China Medical University, S):7657-7672. doi:10.2147/CMAR.S214697

s50.Wen X-M, Luo T, Jiang Y, et al. Zyxin (ZYX) promotes invasion and acts as a biomarker for aggressive phenotypes of human glioblastoma multiforme. Laboratory investigation; a journal of technical methods and pathology. 2020;100(6):812-823. doi:10.1038/s41374-019-0368-9

s51.Xavier-Magalhaes A., Goncalves C.S., Fogli A., et al. The long non-coding RNA HOTAIR is transcriptionally activated by HOXA9 and is an independent prognostic marker in patients with malignant glioma. Oncotarget. 2018;9(21):15740-15756. doi:10.18632/oncotarget.24597

s52. Xu R, Han M, Xu Y, et al. Coiled-coil domain containing 109B is a HIF1alpha-regulated gene critical for progression of human gliomas. Journal of translational medicine. 2017;15(1):165. doi:10.1186/s12967-017-1266-9

s53. Yadav AK, Renfrow JJ, Scholtens DM, et al. Monosomy of chromosome 10 associated with dysregulation of epidermal growth factor signaling in glioblastomas. JAMA. 2009;302(3):276-289. doi:10.1001/jama.2009.1022

s54. Yeung YT, Fan S, Lu B, et al. CELF2 suppresses non-small cell lung carcinoma growth by inhibiting the PREX2-PTEN interaction. Carcinogenesis. 2020;41(3):377-389. doi:10.1093/carcin/bgz113

s55. Yi G-Z, Xiang W, Feng W-Y, et al. Identification of Key Candidate Proteins and Pathways Associated with Temozolomide Resistance in Glioblastoma Based on Subcellular Proteomics and Bioinformatical Analysis. BioMed research international. 2018;2018(101600173):5238760. doi:10.1155/2018/5238760

s56.Zeng A., Yin J., Wang Z., et al. miR-17-5p-CXCL14 axis related transcriptome profile and clinical outcome in diffuse gliomas. Oncolmmunology. 2018;7(12):e1510277. doi:10.1080/2162402X.2018.1510277

s57.Zhai L, Ladomersky E, Lauing KL, et al. Infiltrating T Cells Increase IDO1 Expression in Glioblastoma and Contribute to Decreased Patient Survival. Clinical cancer research: an official journal of the American Association for Cancer Research. 2017;23(21):66506660. doi:10.1158/1078-0432.CCR-17-0120

s58.Zhang Y, Cruickshanks N, Yuan F, et al. Targetable T-type Calcium Channels Drive Glioblastoma. Cancer research. 2017;77(13):3479-3490. doi:10.1158/0008-5472.CAN16-2347 